\title{
Drug Addiction and Substance Abuse in Rural New Hampshire
}

\author{
Donna Driscoll \\ Plymouth State University Nursing Health and Human Enrichment Cluster, Plymouth, NH, USA \\ Email: dldriscoll@plymouth.edu
}

How to cite this paper: Driscoll, D. (2019) Drug Addiction and Substance Abuse in Rural New Hampshire. Open Access Library Journal, 6: e5093.

https://doi.org/10.4236/oalib.1105093

Received: December 4, 2018

Accepted: March 5, 2019

Published: March 8, 2019

Copyright $\odot 2019$ by author(s) and Open Access Library Inc.

This work is licensed under the Creative Commons Attribution International License (CC BY 4.0).

http://creativecommons.org/licenses/by/4.0/

\begin{abstract}
Drug addiction is a problem in all areas of the United States. In every town and city you can probably find a certain population with this issue. Drug abuse and heroin overdoses have hit our small New England community hard in the past five years. Working in the Emergency Department I see many people with drug addiction. This issue affects the addicts as well as their family and friends in numerous ways. Addicts and their families face poor health, lost income, poverty, lack of healthcare, and most of all the pain of losing a loved one to drug addiction or death.
\end{abstract}

\section{Subject Area \\ Drugs \& Devices}

\section{Keyword}

Drug Addiction

\section{Drug Addiction in the United States}

Drug addiction has become a major problem in all areas of the United States. This article discusses the health issues, identifies high risk populations and describes adverse health outcomes due to drug addiction. This issue affects the addicts as well as their family and friends in numerous ways. Addicts and their families face poor health, lost income, poverty, lack of healthcare, and most of all the pain of losing a loved one to drug addiction or death [1].

\subsection{Health Issues}

The adverse health outcomes for people with substance abuse include teenage pregnancy, HIV/AIDS, STDs, domestic violence, child abuse, motor vehicle crashes, physical fights, crime, homicide and suicide [1]. 


\subsection{Identification of High-Risk Population}

Substance abuse can have a major impact on the patients, their families and the community. Substance abuse significantly impacts physical, mental and public health problems. To understand substance abuse you need to see it as a set of related conditions associated with consumption of mind and behavior altering substances. These substances have a negative behavioral and health outcome. According to Healthy People 2020,

"Social attitudes and political and legal responses to the consumption of alcohol and illicit drugs make substance abuse one of the most complex public health issues" [1].

There is a relationship between mental illness and substance abuse. These patients need a primary care provider that will monitor drug behavior and obtain a mental health screening, as this could benefit the patients [2].

A high-risk population in the rural New Hampshire community where I work is substance abuse and an increase in heroin overdoses. Heroin can be injected into a vein, smoked or snorted [3]. This is a high-risk population; heroin in combination with alcohol can cause a dangerous slowdown of the heart rate and breathing, which may result in coma and death [3]. This adverse health outcome has increased in Littleton, $\mathrm{NH}$ and its surrounding towns in the past five years and is a significant community concern.

According to the National Institute on Drug Abuse the most commonly abused drugs are alcohol, bath salts, club drugs, cocaine, hallucinogens, heroin, inhalants, K2 Spice, Marijuana, Ecstasy, Methamphetamine, prescription drugs, cold medicines, steroids, and nicotine [3].

The epidemiologic triangle for substance abuse shows the agent, the host, and the environment. In the case of substance abuse the agent is the person and the drug, the host or "who" could be the social issues and disease process of the addiction and the environment includes all the environmental external factors that cause or allow disease processes [4].

The use of the Injury Prevention Model can also be applied to the issue of substance abuse; this triangle replaces host for injured person, replaces agent for energy, and environment for physical or social environment [5].

\section{Adverse Health Outcomes}

Physically a patient with substance abuse may also have numerous symptoms of malnutrition, dehydration, liver and kidney disease, dental caries and abscesses, decreased cognitive ability and integumentary lesions as well as a lack of hygiene in many cases.

The adverse health outcomes of the heroin addict include pregnancy, miscarriage, low birth weight, neonatal abstinence syndrome, risk of HIV, hepatitis and other infectious diseases from shared needles. Long-term effects include collapsed veins: abscess, infection of the lining and valves of the heart, constipation and stomach cramps, liver or kidney disease, and pneumonia [3]. 
Withdrawal from heroin includes symptoms such as restlessness, muscle and bone pain, insomnia, diarrhea, vomiting, cold flashes and leg twitching [3].

The National Survey on Drug Use and Health (NSDUH) states that in 2011 approximately 20.6 million people aged 12 and older were classified with substance abuse dependence in the past year, that is 8 percent of the population in that age group [6].

The distribution frequency and pattern show that in (2011) 426,000 people in the United States are experiencing substance abuse or addiction to heroin with the age of first using illicit drugs at 14 years old or younger [6].

Determinants nationally of substance abuse include: The rate of males suffering from substance abuse is double that of females and lower in the Asian population than other minorities. Specified populations: People with substance abuse issues have a lower educational level and have a higher rate of unemployment and being involved in the criminal justice system The geographic area of substance abuse shows that for people aged 12 or older 8.9 percent live in the West, 8.6 percent in the Northeast, 8.3 percent in the Midwest, and 7.0 percent in the south. Large metropolitan counties show 8.4, small metropolitan counties show 8.2 percent and 6.3 in nonmetropolitan counties [6].

Health-related states or events: over 21.6 million people aged 12 or older received treatment for an illicit drug or alcohol problem in 2011 in the United States. The National Survey on Drug use reports that the data for 2011 showed higher numbers of heroin users and inmates than prior years. These findings support the anecdotal reports that are suggesting an increase in heroin use among young people. The 2011 data on heroin users in the United States is 289,000, an increase of 109,000 from 2005 [6]. Heroin overdoses death rate has doubled in 28 states from 2010 to 2012 [4].

Americas health ranking states that NH shows 13.4 deaths per 1000 for drug deaths over a three-year average, this is due to death whether intentional or unintentional or undetermined [7].

\section{Conclusions}

Drug addiction and substance abuse is an important population to be aware of as we assess our patients and the aspects of caring for this vulnerable population. When we see that our patient is either over using the pain medication or shows signs of addiction or substance abuse we need to be proactive and assist them in this journey of addiction and the road to recovery.

Commitment to recovery as a basic requirement for drug treatment is important to achieve the goal of a drug free life. We all know that the first step is that the person actually needs to want to make the change and we can help by having a non-judgmental approach [8]. We need to always be looking at the evidence and striving for the best practice for our patients. New research on a drug vaccine that blocks the relapse of heroin addiction in rats shows promising results. There is hope out there for our patients through research, a non-judgmental ap- 
proach to client care, collaboration and open communication between care providers and our clients [9].

\section{Conflicts of Interest}

The author declares no conflicts of interest regarding the publication of this paper.

\section{References}

[1] Healthy People 2020 (2015) U. S. Department of Health and Human Services. http://www.healthypeople.gov/2020/topics-objectives/topic/Access-to-Health-Servic es

[2] Harris, K.M. and Edlund, M.J. (2005) Use of Mental Health Care and Substance Abuse Treatment among Adults with Co-Occurring Disorders. Psychiatric Services, 56, 954-959. https://doi.org/10.1176/appi.ps.56.8.954 https://www.ncbi.nlm.nih.gov/pubmed/16088012

[3] Drug Abuse (2015) Commonly Abused Drugs Charts. National Institute on Drug Abuse (NIDA).

http://www.drugabuse.gov/drugs-abuse/commonly-abused-drugs-charts-0\#heroin

[4] CDC (2015) Understanding the Epidemiologic Triangle through Infectious Disease. http://www.cdc.gov

[5] Injury Prevention, Indian Health Service Portland Area, the 5 Public Health Principles.

[6] Results from the 2011 National Survey on Drug Use and Health Summary of National Findings. U.S. Department of Health and Human Services.

[7] Americas Health Ranking, United Health Foundation. State Data, New Hampshire. http://www.americashealthrankings.org/NH

[8] Andersen, D. (2014) Storytelling in Drug Treatment: How Professionals Make Sense of What They Consider Inauthentic Client Claims. Contemporary Drug Problems, 41, 491-506. https://doi.org/10.1177/0091450914567118

[9] Nature.com (2013) Addiction Research: Drug Vaccine Blocks Rat Relapse. Nature, 497, 290. https://doi.org/10.1038/497290c 